\title{
Expresión de los Genes de Inmunoglobulina A y Citoquinas Asociadas IL-5, IL-6 y TGF- $\beta$ en Mucosa Intestinal de Crías de Alpacas (Vicugna pacos) Vacunadas con Antígeno Clostridial
}

\author{
Gene Expression of Immunoglobulin a And Associates Cytokines \\ (IL-5, IL-6 and TGF- $\beta$ ) in Intestinal Mucosa of Baby Alpacas (Vicugna pacos) \\ Vaccinated With Clostridial Antigen
}

Joan Reyes Z. ${ }^{1}$, Alberto Manchego S. ${ }^{1,4}$, Gina Castro S. ${ }^{1}$, César Burga C., Danilo Pezo C. ${ }^{3}$, Nieves Sandoval C. ${ }^{2}$, Mercy Ramírez V. ${ }^{1}$, Hermelinda Rivera G. ${ }^{1}$

\section{Resumen}

\begin{abstract}
El estudio tuvo como objetivo determinar y comparar los niveles de expresión de los genes de IgA y citoquinas asociadas IL-5, IL-6 y TGF- $\beta$ en la mucosa intestinal de crías de alpaca clínicamente sanas vacunadas oralmente con un antígeno clostridial. Se trabajó con 10 crías no vacunadas (control) y 15 crías vacunadas (dos dosis con intervalo de siete días). El muestreo se hizo a los siete días de la segunda dosis. Asimismo, se consideraron dos subgrupos etarios (15-28 y 35-56 días de edad en el momento de la toma de la muestra). Se tomaron segmentos intestinales de $2 \mathrm{~cm}$ de longitud de la porción media del yeyuno y se almacenaron a $-196^{\circ} \mathrm{C}$. Se realizó la extracción de ARN total y luego se sintetizó el ADN complementario (ADNc) por transcripción inversa. Luego se realizó la PCR en tiempo real utilizando cebadores específicos para IL-5, IL-6, TGF- $\beta$ y el exón 3 de IgA. Se realizó la evaluación de la expresión relativa mediante el método $2^{-\Delta \Delta C t}$. Las crías vacunadas con antígeno clostridial tuvieron una mayor expresión de IgA (control: 275.3 veces; vacunados: 710.2 veces más que el calibrador $)(\mathrm{p}=0.005)$. Las crías vacunadas del subgrupo 15-28 días de edad expresaron IL-5, IL-6 y TGF- $\beta$ en 1.96, 4.78 y 2.87 veces más que el calibrador, respectivamente, habiendo diferencia significativa con el grupo control $(\mathrm{p}<0.05)$. Se concluye que la administración de antígeno clostridial como vacuna oral en crías de alpaca en los primeros 14 días de edad promueve una mayor expresión de los genes de IgA y citoquinas asociadas IL-5, IL-6 y TGF- $\beta$ a nivel de mucosa intestinal.
\end{abstract}

Palabras clave: crías de alpaca; antígeno clostridial; inmunoglobulina A; RT-PCR en tiempo real; cuantificación relativa

\footnotetext{
${ }^{1}$ Laboratorio de Microbiología y Parasitología Veterinaria, ${ }^{2}$ Laboratorio de Histología, Embriología y Patología Veterinaria, Facultad de Medicina Veterinaria, Universidad Nacional Mayor de San Marcos, Lima, Perú

${ }^{3}$ Estación Experimental del Centro de Investigación IVITA, Maranganí, Cusco, Perú

${ }^{4}$ E-mail: amanchegos@unmsm.edu.pe
}

Recibido: 8 de diciembre de 2016

Aceptado para publicación: 26 de mayo de 2017 
The aim of this study was to determine and compare the expression levels of IgA genesand associated cytokines I L-5, IL-6 and TGF- $\beta$ in the intestinal mucosa of clinically healthy baby alpaca, that were orally vaccinated with a clostridial antigen. Ten unvaccinated baby alpacas (control) and 15 vaccinated (two doses with a seven-day interval) were used. Sampling was done seven days after the second dose. Likewise, two age subgroups (15-28 and 35-56 days of age at the time of sampling) were considered. Intestinal segments of $2 \mathrm{~cm}$ in length were taken from the middle portion of the jejunum and stored at $-196{ }^{\circ} \mathrm{C}$. Total RNA extraction was performed and the complementary DNA (cDNA) was synthesized by reverse transcription. Subsequently, real-time PCR was run using specific primers for IL-5, IL-6, TGF- $\beta$ and exon 3 of IgA. Relative expression evaluation was performed using the $2^{-\triangle \Delta A ̈ C t}$ method. Vaccinated animals with clostridial antigen had a greater expression of IgA (control: 275.3 fold, vaccinated: 710.2 fold more than the calibrator) $(p=0.005)$. The vaccinated alpacas of the 15-28 day subgroup expressed IL-5, IL-6 and TGF- $\beta$ at 1.96, 4.78 and 2.87 fold higher than the calibrator, respectively, with a significant difference with the control group $(\mathrm{p}<0.05)$. It is concluded that the administration of clostridial antigen as an oral vaccine in baby alpacas in the first 14 days of age promotes a greater expression of the IL-5, IL-6, TGF- $\beta$ and IgA genes at the intestinal mucosa level.

Key words: baby alpaca; clostridial antigen; immunoglobulin A; real-time RT-PCR; relative quantification

\section{INTRODUCCIÓN}

Las enfermedades entéricas representan una de las principales causas de mortalidad y morbilidad en crías de alpacas en las regiones altoandinas, siendo la enterotoxemia la enfermedad con mayor mortalidad (Moro, 1987). La enterotoxemia es causada por Clostridium perfringens, principalmente por el tipo A y en menor proporción por el tipo C. Este patógeno infecta a las alpacas por vía oral y se establece en el yeyuno e íleon, produciendo las toxinas $\alpha$ y $\beta 2$, responsables del cuadro enterotoxémico (Pérez et al., 2012). La enfermedad afecta a crías de 2 a 9 semanas de edad, logrando alcanzar una mortalidad de 70\%. La presentación clínica corresponde una toxemia con signos entéricos y nerviosos de curso rápido, generando una muerte súbita (Ramírez et al., 1985).

La inmunoglobulina A(IgA) es el isotipo más abundante e importante en la inmunidad local a nivel de la mucosa intestinal, evitando la penetración de los antígenos, aglutinándolos en el epitelio, lo cual promueve una protección no inflamatoria en un tejido altamente antigénico (exclusión inmune); además de su habilidad de transportarse a través de células epiteliales y su resistencia a proteasas (Cerutti y Rescigno, 2008). La IgA es producida por linfocitos B activados en los tejidos linfoides asociados a mucosa intestinal, luego de un proceso de estimulación por citoquinas como IL-5, IL-6 y TGF $\beta$ (Kawanishi y Joseph, 1991; Sonoda et al., 1992; Borsutzky et al., 2004), este último de vital importancia en el proceso de cambio de cadena pesada hacia el tipo $\alpha$ en los linfocitos B (van Vlasselaer $e t$ al., 1992).

Existen vacunas sistémicas contra la enterotoxemia confiriendo protección a base de inmunoglobulina $\mathrm{G}$, que actúan cuando el microorganismo ha proliferado y superado la inmunidad de la mucosa. La vacuna oral propuesta en este trabajo, busca aumentar la producción de IgA en la mucosa intestinal, impidiendo la adhesión de los patógenos a los epitelios intestinales y la colonización. 


\section{Materiales y Métodos}

\section{Preparación del Antígeno Clostridial}

Los antígenos de $C$. perfringens se obtuvieron de todas las cepas de campo aisladas de crías de alpacas muertas con diagnóstico de enterotoxemia durante la campaña de parición del 2014 en el distrito de Maranganí, Cusco. Las cepas fueron mantenidas con resiembras en caldo tioglicolato hasta la preparación del antígeno costridial.

Se realizó tinción Gram y pruebas bioquímicas para su identificación. Fueron sembradas en caldo tioglicolato e incubadas en condiciones de anaerobiosis a $37^{\circ} \mathrm{C}$ por $48 \mathrm{~h}$. El cultivo fue inactivado con formalina a una concentración de $0.05 \%$ por $1 \mathrm{~h}$, donde se centrifugó para separar la fase celular de la fase líquida. De esta última, se precipitaron las proteínas solubles totales empleando ácido tricloroacético (TCA Merck, EEUU) y se llevó a refrigeración por $24 \mathrm{~h}$. Posteriormente, se centrifugó y se lavaron los restos con acetona (Merck, EEUU) para volver a centrifugar. El precipitado proteico de la fase líquida y celular fue resuspendido en PBS y sometido a proceso de diálisis en solución salina a $4{ }^{\circ} \mathrm{C}$. Se obtuvo finalmente una solución de antígenos somáticos más exotoxina purificada, y se determinó la concentración antigénica de la muestra dializada empleando el equipo Qubit ${ }^{\circledR}$ 2.0 Fluorometer (Invitrogen, EEUU) y la prueba comercial Qubit ${ }^{\circledR}$ Protein Assay Kit, siguiendo las instrucciones del fabricante. Finalmente, se ajustó la dosis de antígeno a $13 \mathrm{mg} / \mathrm{ml}$ (More, 2013).

El antígeno proteico fue mezclado con un inmunomodulador derivado de la vitamina A para obtener una vacuna oral a una concentración de $13 \mathrm{mg} / \mathrm{ml}$ de antigenos totales y $0.2 \mathrm{mM} / \mathrm{ml}$ de inmunomudulador. Se utilizó la vacuna a un volumen de $1 \mathrm{ml} / \mathrm{kg}$ de peso vivo de la cría de alpaca.

\section{Animales y Vacunación}

Se evaluaron 25 crías de alpacas clínicamente sanas, entre 1 y 40 días de edad, de las variedades Suri y Huacaya, sin distinción de sexo, del centro de crianza de alpacas de La Raya (Centro de Investigación IVITAMaranganí) y de comunidades alpaqueras aledañas, localizadas en la provincia de Canchis, Cusco (Perú), durante la campaña de parición de 2015.

Los animales fueron distribuidos en dos grupos: un grupo control (no vacunado) de 10 crías, y el otro grupo vacunado de 15 crías. En el momento de la toma de muestra, cada grupo fue subdividido en dos subgrupos etarios: $15-28$ y 36-56 días de edad. Para el análisis de expresión genética se incluyeron tres fetos a término de gestación, como animales calibradores, representando el valor basal de expresión genética de los genes en estudio.

La vacuna fue administrada vía oral, con una jeringa conteniendo el antígeno clostridial $(13 \mathrm{mg} / \mathrm{ml}$. El protocolo de vacunación consideró la aplicación de dos dosis con siete días de intervalo. Las muestras fueron colectadas a los siete días de la segunda dosis.

\section{Muestras}

Los animales fueron manejados bajo el protocolo de Autorización N. ${ }^{\circ} 2009-001$ del Comité de Ética y Bienestar Animal de la Facultad de Medicina Veterinaria de la Universidad Nacional Mayor de San Marcos. Para el sacrificio de los animales se utilizó $1.5 \mathrm{mg} / \mathrm{kg}$ de xilacina (Rompun ${ }^{\circledR}$ ) y $7.5 \mathrm{mg} / \mathrm{kg}$ de ketamina (Vetalar $\left.{ }^{\circledR}\right)$, vía intramuscular, seguido por una sobredosis de $50 \mathrm{mg} / \mathrm{kg}$, vía endovenosa, de pentobarbital sódico (Halatal ${ }^{\circledR}$.

Inmediatamente después de la eutanasia de los animales, se colectaron segmentos intestinales de $2 \mathrm{~cm}$ de longitud de la porción 
Cuadro 1. Oligonucleótidos diseñados para el estudio

\begin{tabular}{|c|c|c|c|}
\hline & $\begin{array}{l}\text { Longitud } \\
(\mathrm{pb})^{1}\end{array}$ & Secuencia $\left(5^{\prime}-3^{\prime}\right)$ & $\begin{array}{c}\text { Temp de } \\
\text { hibridación }\left({ }^{\circ} \mathrm{C}\right)\end{array}$ \\
\hline \multirow{2}{*}{$\operatorname{IgA}$ Exon3 } & \multirow{2}{*}{164} & F: $5 ` A A G G A C G T G C T G G T T C G A T$ 3` & 59.33 \\
\hline & & R: $5^{`}$ CCCACCATGCAGGAGTAGTT $3 `$ & 59.38 \\
\hline \multirow{2}{*}{ IL-5 } & \multirow{2}{*}{200} & F: 5 GATAGGCGAYGGGAACTTGA 3` & 60.04 \\
\hline & & R: 5 'GCCATCTTYCTCCTCCACAC 3’ & 59.66 \\
\hline \multirow{2}{*}{ IL-6 } & \multirow{2}{*}{197} & F: 5 'CCTGGTGATGGCTACTGCTT 3` & 60.28 \\
\hline & & R: 5 `ACAGTGCCTCCTTGCTGTTT 3` & 59.91 \\
\hline \multirow{2}{*}{ TGF- $\beta$} & \multirow{2}{*}{185} & F: 5'GAGGTGATCTYGCCACCATT 3’' & 59.93 \\
\hline & & R: 5 'GTCCTTGCGGAAGTCAATGT 3’ & 60.12 \\
\hline \multirow{2}{*}{ GAPDH } & \multirow{2}{*}{201} & F: 5`ATCACTGCCACCCAGAAGAC 3` & 60.12 \\
\hline & & R: 5 'GCACGTCAGATCCACAACAG 3` & 60.32 \\
\hline
\end{tabular}

${ }^{1}$ Pares de bases

media del yeyuno y lavadas en suero fisiológico estéril al $0.9 \%$ para eliminar restos de contenido intestinal potencialmente inhibidores de las técnicas moleculares. Las muestras fueron colocadas en crioviales estériles de $2 \mathrm{ml}$ y conservados en nitrógeno líquido $\left(-196^{\circ} \mathrm{C}\right)$, hasta su procesamiento en el Laboratorio de Virología y Diagnóstico Molecular de la Facultad de Medicina Veterinaria, Universidad Nacional Mayor de San Marcos, Lima.

\section{Oligonucleótidos}

Se emplearon oligonucleótidos específicos para el exón 3 de la IgA y citoquinas asociadas (IL-5, IL-6 y TGF- $\beta$ ). Se incluyeron oligonucleótidos específicos para la amplificación de transcritos de GAPDH como gen interno para la normalización de la cuantificación relativa. Estos oligonucleótidos fueron diseñados por el programa Primer3 output (www.primer3.com) y el programa BLAST del NCBI (www.ncbi.nlm.nih.gov/blast/), en base de secuencias de ARNm de alpacas publicadas en el GENBANK (Cuadro 1).

\section{Extracción y Cuantificación del ARN Total}

Los segmentos intestinales fueron descongelados sobre un recipiente de hielo, cortados y pesados para obtener $1 \mathrm{~g}$ de cada muestra. Fueron molidos a $4{ }^{\circ} \mathrm{C}$ con pilón y mortero estériles. Se empleó el «Trizol® Reagent» (Invitrogen, EEUU) siguiendo las instrucciones del fabricante para obtener el ARN total de las muestras presente en la fase acuosa de la reacción final. Esta fue transferida a una membrana de sílica utilizando el kit comercial «PureLink ${ }^{\mathrm{TM}}$ Micro-to-Midi Total RNA Purification System» (Invitrogen, EEUU), acorde a las instrucciones del fabricante. El producto final de ARN fue eluído en $60 \mu 1$ de agua libre de nucleasas.

La cuantificación del ARN total se realizó mediante lectura por fluorometría en el equipo Qubit ${ }^{\circledR} 2.0$ Fluorometer calibrado (Invitrogen, EEUU) empleando el kit comercial «Quant-iT ${ }^{\mathrm{TM}} \mathrm{RNA}$ Assay» (Invitrogen, EEUU), siguiendo las instrucciones del fa- 
bricante. Se homogenizaron las muestras a una concentración de $1 \mu \mathrm{g}$ de ARN total extraído.

\section{Síntesis de ADN Complementario por RT-PCR}

Se empleó el kit comercial «SuperScript $^{\mathrm{TM}}$ III First-Strand Synthesis SuperMix for qRT-PCR» (Invitrogen, EEUU), siguiendo las instrucciones del fabricante. El procedimiento se realizó en el termociclador Applied Biosystems ${ }^{\circledR} 2720$, programado por un solo ciclo con el siguiente protocolo: $25^{\circ} \mathrm{C}$ por 10 $\min , 50^{\circ} \mathrm{C}$ por $30 \mathrm{~min}, 85^{\circ} \mathrm{C}$ por $5 \mathrm{~min}$ y a $4{ }^{\circ} \mathrm{C}$ indefinidamente para enfriar la muestra. Luego se añadió $1 \mu l$ de RNasa $H$ de $E$. coli (proveído por el kit), a cada pocillo y se incubó a $37^{\circ} \mathrm{C}$ por $20 \mathrm{~min}$ para destruir la molécula ARN del híbrido ARN:ADNc. El ADNc obtenido fue congelado a $-70{ }^{\circ} \mathrm{C}$ hasta su uso en la reacción de PCR Tiempo Real.

\section{PCR en Tiempo Real}

Se empleó el kit comercial «SYBR ${ }^{\circledR}$ GreenER $^{\mathrm{TM}}$ qPCR SuperMix Universal», siguiendo las instrucciones del fabricante. $\mathrm{La}$ reacción utilizó la polimerasa Hot Start Taq, el agente intercalante «Sybr Green I» como fluoróforo intercalante de cadenas dobles de ADN, y el colorante Rox como referencia pasiva (todos proveídos por el kit). El procedimiento se realizó en el termociclador Applied Biosystems ${ }^{\circledR} 7500$ y se programó con el siguiente protocolo: $50^{\circ} \mathrm{C}$ por $2 \mathrm{~min}, 95^{\circ} \mathrm{C}$ por 10 min (desnaturalización inicial y activación de la polimerasa), seguido de 45 ciclos de $95^{\circ} \mathrm{C}$ por $15 \mathrm{~s}, 60^{\circ} \mathrm{C}$ por $60 \mathrm{~s}$ y lectura de placa; y el análisis de temperatura de disociación desde $65^{\circ} \mathrm{C}$ hasta $90{ }^{\circ} \mathrm{C}$, con incrementos de temperatura de $0.3^{\circ} \mathrm{C}$ cada $30 \mathrm{~s}$, finalizando la reacción a $8{ }^{\circ} \mathrm{C}$ indefinidamente para mantener los productos. El ensayo fue realizado por triplicado y los resultados fueron evaluados a través del Software 7500 Fast Real-Time PCR Systems v. 2.0.1 para obtener los promedios de Ct (ciclo umbral) y Tm (temperatura de disociación) de cada muestra.

\section{Cuantificación Relativa}

Se empleó el Método Ct comparativo $2^{-\Delta \Delta C t}$ como técnica de cuantificación de la expresión relativa de genes detectables a través de RT-PCR en tiempo real (Livak y Smittdgen, 2001), usando como calibrador a tres fetos de alpaca a término de gestación y como control interno al gen de Gliceraldehído3-fosfato deshidrogenasa (GAPDH).

\section{Análisis Estadístico}

Se empleó la prueba de Shapiro-Wilk para demostrar que los datos no siguen la distribución normal, empleando, por lo tanto, la prueba no paramétrica U de Mann WhitneyWilcoxon para estimar diferencias entre individuos no vacunados y vacunados. Los resultados se presentan como el promedio de los grupos evaluados. Todas las pruebas fueron realizadas en el programa estadístico Stata/SE 12.0.

\section{Resultados}

El análisis de la RT-PCR en Tiempo Real del ARNm del gen GAPDH, IL-5, IL6 , TGF- $\beta$ e IgA mostró una homogeneidad en las curvas de amplificación y curvas de disociación de un pico único sin presencia de productos inespecíficos con valores de temperatura de disociación cercanas entre sí (Cuadro 2).

Los resultados del análisis de la cuantificación relativa del ARNm del exón 3 de IgA mostraron que el nivel promedio de expresión del grupo no vacunado y grupo vacunado fue de 275.3 y 710.2 veces respecto del calibrador, respectivamente, existiendo diferencia significativa $(\mathrm{p}=0.005)$. Con relación a los subgrupos etarios, el subgrupo de 15 a 28 días de edad (3 a 4 semanas), el nivel promedio de expresión del grupo no vacunado y grupo vacunado fue de 196.2 y 766.0 veces respecto del calibrador $(\mathrm{p}=0.0192), \mathrm{y}$ en el subgrupo de 36 a 56 días de edad (6-8 


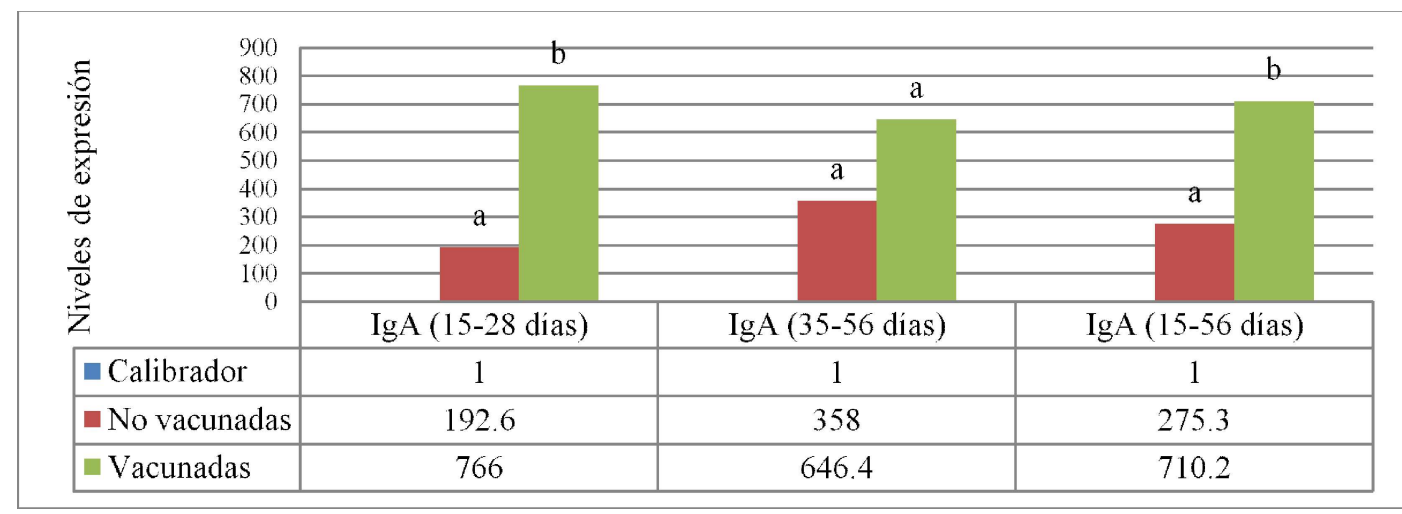

Figura 1. Cuantificación relativa del ARNm del exón 3 de IgA en mucosa intestinal de crías de alpacas vacunadas y no vacunadas respecto al calibrador ${ }^{a, b}$ Superíndices diferentes indican diferencia significativa $(p<0.05)$

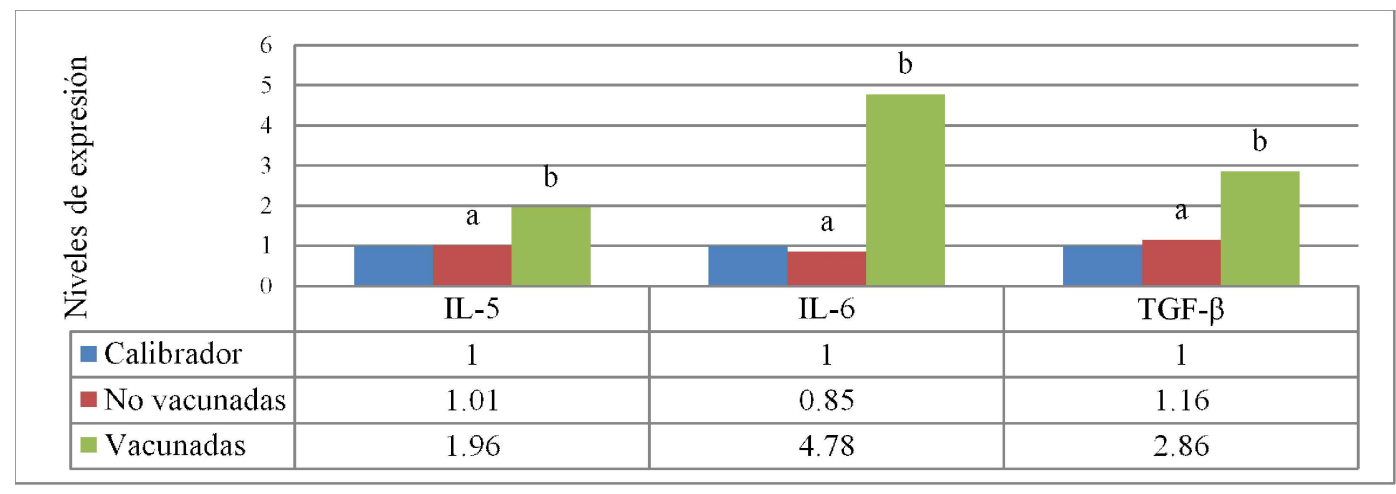

Figura 2. Cuantificación relativa del ARNm de IL-5, IL-6 y TGF- $\beta$ en mucosa intestinal de crías de alpacas vacunadas y no vacunadas respecto al calibrador (15-28 días de edad)

$a, b$ Superindices diferentes indican diferencia significativa $(p<0.05)$

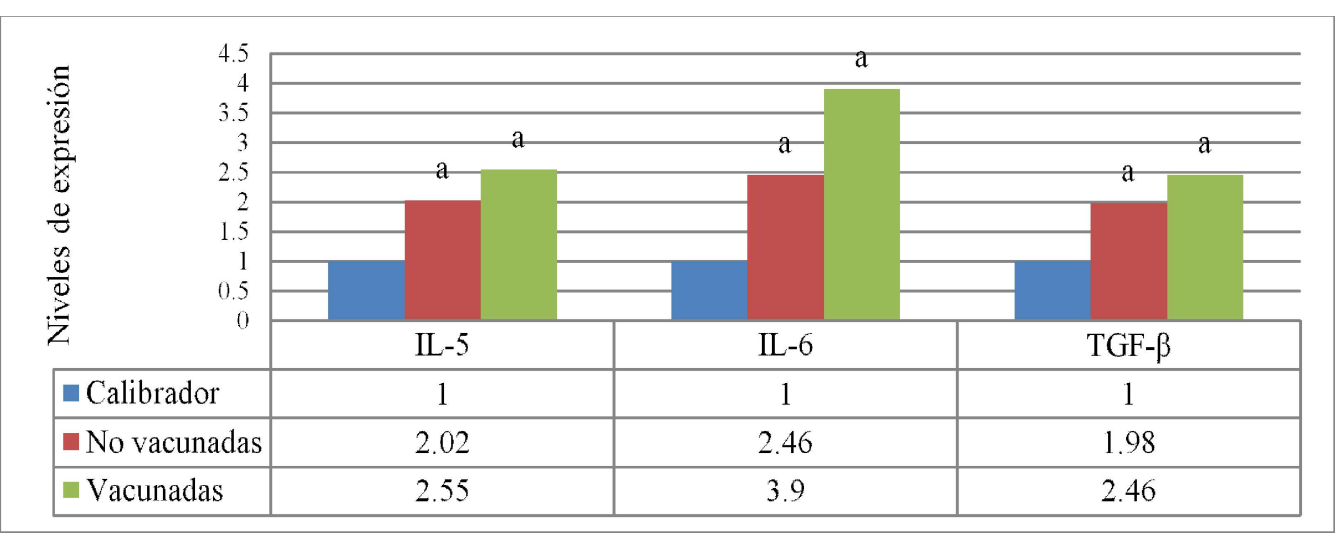

Figura 3. Cuantificación relativa del ARNm de IL-5, IL-6 y TGF- $\beta$ en mucosa intestinal de crías de alpacas vacunadas y no vacunadas respecto al calibrador (35-56 días de edad)

${ }^{a, b}$ Superindices diferentes indican diferencia significativa $(p<0.05)$ 
Cuadro 2. Ciclo umbral $(\mathrm{Ct})$ y temperatura de disociación $(\mathrm{Tm})$ de productos amplificados

\begin{tabular}{cccc}
\hline Gen & Ct (no vacunados) & $\mathrm{Ct}$ (vacunados) & $\mathrm{Tm}\left({ }^{\circ} \mathrm{C}\right)$ \\
\hline IgA Exon3 & $18.45-21.54$ & $15.77-20.79$ & $86.77-87.34$ \\
IL-5 & $31.18-33.13$ & $29.40-32.06$ & $74.81-75.53$ \\
IL-6 & $28.14-30.62$ & $24.57-29.09$ & $78.20-78.95$ \\
TGF- $\beta$ & $21.59-24.63$ & $20.75-23.54$ & $84.39-85.58$ \\
GAPDH & $17.54-20.91$ & $17.51-19.92$ & $85.98-86.67$ \\
\hline
\end{tabular}

semanas), el nivel promedio de expresión del grupo no vacunado y grupo vacunado fue de 358.0 y 646.4 veces respecto del calibrador, no encontrándose diferencia significativa (Figura 1).

Considerando el análisis del subgrupo etario de 15-28 días de edad (3-4 semanas), los resultados para IL-5 mostraron niveles de expresión de 1.01 y 1.96 veces lo expresado por el calibrador para el grupo no vacunado y vacunado, respectivamente $(p=0.0192)$. En el caso de IL-6 fue de 0.85 y 4.78 veces respecto del calibrador para el grupo no vacunado y vacunado, respectivamente $(\mathrm{p}=0.0128)$. En el caso de TGF- $\beta$ fue de 1.16 y 2.86 veces respecto del calibrador para el grupo no vacunado y vacunado, respectivamente $(\mathrm{p}=0.0404)$ (Figura 2).

Considerando el análisis del subgrupo etario de 36-56 días de edad (6-8 semanas), los resultados para IL-5 mostraron niveles de expresión de 2.02 y 2.55 veces lo expresado por el calibrador para el grupo no vacunado y vacunado, respectivamente $(\mathrm{p}=0.6842)$. En el caso de IL-6 fue de 2.46 y 3.90 veces respecto del calibrador para el grupo no vacunado y vacunado, respectivamente $(\mathrm{p}=0.9353$ ). En el caso de TGF- $\beta$ fue de 1.98 y 2.46 veces respecto del calibrador para el grupo no vacunado y vacunado, respectivamente $(p=0.5698)$, existiendo diferencias significativas en este subgrupo (Figura 3 ).

\section{Discusión}

La evaluación por grupos determinó diferencia significativa en la expresión del exón 3 de $\operatorname{IgA}$ entre los grupos vacunados y no vacunados. En forma similar, en el subgrupo etario de 3-4 semanas se encontró que los niveles de expresión estaban influenciados positivamente por la vacuna. Dionisio et al. (2014) evaluó la cinética de expresión del exón 1 de IgA en crías de alpacas sanas y enfermas encontrando una tendencia de expresión constante en los sanos y niveles superiores en los enfermos, la cual es de la misma proporción a los resultados de los no vacunados y vacunados en este estudio, indicando una similitud de expresión de IgA en los animales vacunados en comparación con animales enfermos.

Estas diferencias de expresión de los genes de $\operatorname{IgA}$ del presente estudio revelan estimulación y activación de la respuesta humoral a nivel intestinal de los vacunados, promovidos por la acción del inmunógeno administrado, desarrollando una protección de las mucosas mediante esta inmunoglobulina, sabiendo que también favorece una respuesta inmune celular (More, 2013). Sin embargo, los niveles de expresión en el subgrupo etario de 6-8 semanas no se vieron afectados por la vacuna, aunque llegaron a presentar un aumento en su expresión. La edad podría estar 
relacionada a la respuesta, si se considera que el sistema inmune de mucosas a nivel intestinal durante las primeras semanas de vida se enfrenta continuamente a microorganismos del medio ambiente, presentes en suelo, pasturas o pezones contaminados de la madre. Así mismo, desde la segunda a tercera semana de edad, el animal empieza a consumir pasturas que conlleva a un cambio de la microflora intestinal, activando una respuesta inmune de mucosa, tanto innata como adaptativa, poniendo en marcha mecanismos madurativos y adaptativos para mantener una barrera mucosa intestinal íntegra y activa e incorporar una población bacteriana normal estable (Ruiz et al., 2010).

Los niveles de expresión de IL-5 en el subgrupo de 3-4 semanas se encuentran aumentados en los vacunados, ya que la IL-5 es identificada como factor importante en la producción de IgA producida por la célula B. Estudios in vivo en ratones deficientes de IL-5 revelaron una reducción significativa en la concentración de IgA intestinal en comparación con los que producen IL-5 que sí son capaces de mantener una respuesta normal de IgA ante un estímulo (Fontenele et al., 2006). Por otro lado, el aumento no significativo observado en los vacunados del subgrupo etario de 6-8 semanas pudo deberse a la presencia de parásitos intestinales, ya que esta citoquina es más específica en la diferenciación y liberación de los eosinófilos periféricos y tisulares, importante en la regulación de las enfermedades gastrointestinales parasitarias (Greenfeder et al., 2001).

Los niveles de expresión del IL-6 se vieron incrementados por la vacuna en el subgrupo etario de 3-4 semanas, ya que los inmunógenos promueven la diferenciación y maduración de los linfocitos $\mathrm{T}$ y $\mathrm{B}$, estimulando la producción de las inmunoglobulinas por parte de las células B para combatir principalmente a patógenos extracelulares (Mestecky et al., 1999). Este incremento no fue significativo en el subgrupo de mayor edad, tal vez debido a que las crías van pro- duciendo un incremento de IgA en la mucosa intestinal por los estímulos de antígenos de la flora normal del intestino, como se observa en el trabajo de Dionisio et al. (2014) en crías de alpacas aparentemente sanas. Este aumento se debe al complejo y dinámico ecosistema bacteriano intestinal y, por tanto, una mayor exposición a componentes de la pared bacteriana que generan un potente estímulo local para la producción de IL-6 (Meijssen et al., 1998), teniendo en cuenta que las alpacas nacen con un sistema inmune ya formado y listo para actuar con el entorno (Roca, 2011). Las células epiteliales intestinales están activamente involucradas en la regulación de los eventos de inflamación intestinal, modulando de ese modo los eventos iniciales de la respuesta inmune adquirida mediante secreción de mediadores pro $\mathrm{y}$ anti inflamatorios, tales como la IL-6 (Kusugami et al., 1995).

Los niveles de expresión del gen TGF$\beta$ se encontraron aumentados en el subgrupo etario de 3-4 semanas vacunado. Herrera (2012) encontró en crías sanas, niveles de expresión de TGF- $\beta$ cercanas a los valores obtenidos, lo que indica un nivel de expresión normal en animales sanos. Esta citoquina contribuye en la generación de células $\mathrm{T}$ reguladoras, la cual representa un sistema de regulación de respuesta frente a antígenos presentados por células presentadoras de antígeno (CPA) en la mucosa intestinal (Takeuchi, 1998). El aumento de esta citoquina estaría jugando un rol importante, además, en la producción de $\operatorname{IgA}$, que es el anticuerpo principal necesario para la inmunidad de las mucosas, mediante la inducción de un cambio hacia ese isotipo en los linfocitos B (Abbas et al., 2015). En el caso de las crías de mayor edad, el aumento de esta citoquina no fue significativo, debido a los procesos inflamatorios provocados por estímulos masivos y constantes de las bacterias comensales intestinales y los antígenos alimentarios, siendo estos niveles un estado fisiológico normal a esta edad (Bardalez et al., 2013). 
La baja expresión de los genes de las citoquinas que estimulan la inmunidad humoral (IL5, IL6 y TGF- $\beta$ ) se ha visto reflejada también en otros trabajos, donde la expresión de estas citoquinas no se encuentra proporcionalmente directa a la producción de la IgA. La expresión de las citoquinas del perfil humoral en alpacas clínicamente sanas muestra una baja expresión en los primeros 47 días de vida (Burga, 2016); sin embargo, a pesar de la poca expresión de estas citoquinas, la producción de IgA se muestra ascendente con la edad, demostrando que no es necesario una alta expresión de las citoquinas asociadas al perfil humoral para producir una elevada cantidad de IgA en las alpacas.

\section{Conclusiones}

- Las crías de alpaca vacunadas contra Clostridium perfringens presentan niveles de expresión de ARNm del gen del exón 3 de IgA significativamente superiores a los animales no vacunados ( 710.2 veces con respecto al calibrador).

- El uso del antígeno clostridial como vacuna oral aplicada a doble dosis en crías de alpacas durante los primeros 14 días de nacido promueve una mayor expresión significativa de los genes de IgA y citoquinas asociadas IL-5, IL-6 y TGF$\beta$ entre la tercera y cuarta semana de edad, en comparación con las no crías no vacunadas.

- Las crías de alpacas vacunadas después de los 21 días de edad generan una mayor, pero no significativa, expresión de genes de IgA y citoquinas asociadas IL5 , IL-6 y TGF- $\beta$ entre la sexta y octava semana de edad, en comparación con las crías no vacunadas.

\section{Agradecimientos}

Los autores agradecen a los criaderos alpaqueros de las comunidades de la provincia de Canchis, Cusco, por su colaboración para la adquisición de los animales utilizados en el presente estudio. El trabajo fue financiado por el Programa Nacional de Innovación para la Competitividad y Productividad (Proyecto N. ${ }^{\circ} 180$ FINCyT-IB 2013).

\section{Literatura Citada}

1. Abbas AK, Lichtman AH, Pillai S. 2015. Inmunología celular y molecular. $8^{\mathrm{a}}$ ed. España: Elsevier. 537 p.

2. Bardález C. Manchego A, Chiok K, Sandoval N, More J, Pezo D, Ramírez M. 2013. Cinética de expresión del factor de necrosis tumoral alfa (TNF- $\alpha$ ) e interleucina 1 alfa (IL-1 $\alpha$ ) en mucosa intestinal de crías de alpaca (Vicugna pacos) sanas y con enteropatía. Rev Inv Vet Perú 24: 381-389. doi: 10.15381/ rivep.v24i3.2588

3. Borsutzky S, Cazac B, Roes J, Guzmán CA. 2004. TGF- $\beta$ receptor signaling is critical for mucosal IgA responses. J Immunol 173: 3305-3309. doi: 10.4049/jimmunol.173.5.3305

4. Burga C. 2016. Expresión de citoquinas de la respuesta Th2 en mucosa intestinal de crías de alpaca. Tesis de Magister. Lima: Univ Nacional Mayor de San Marcos. 86 p.

5. Cerutti A, Rescigno M. 2008. The biology of intestinal immunoglobulin A responses. Immunity 28: 740-750. doi: 10.1016/j.immuni.2008.05.001

6. Dionisio J, Manchego A, Lam Chiok K, Sandoval N, More J, Pezo D, Rivera H. 2014. Cinética de expresión de inmunoglobulina A en el epitelio intestinal de crías de alpacas (Vicugna pacos). Rev Inv Vet Perú 25: 151-161. doi: 10.15381/rivep.v25i2.8486

7. Fontenele AL, Carvalho PG, Ferreira CH, Girão AB, Teixeira MJ, Queiroz JA, Almeida YM. 2006. Avaliação da dosagem de interleucina-5 e imunoglobulina E em pacientes com giardíase com ou sem eosinofilia. Rev Bras Análises Clin 38: 201-206. 
8. Greenfeder S, Umland S, Cuss F, Chapman R, Egan R. 2001. Th2 cytokines and asthma. The role of interleukin-5 in allergic eosinophilic disease. Respir Res 2: 71-79. doi: 10.1186/rr41

9. Herrera AR. 2012. Detección de citoquinas inductora y efectora para la diferenciación y función de linfocitos colaboradores 17 (Th17) en mucosa intestinal de crías de alpacas (Vicugna pacos). Tesis de Magister. Lima: Univ Nacional Mayor de San Marcos. 98 p.

10. Kawanishi H, Joseph K. 1991. IL-4, IL-5 and IL-6 mediated regulation of immunoglobulin (Ig) heavy chain class switching and Ig production by gutassociated lymphoid tissue (GALT) B cells from athymic nude $(\mathrm{nu} / \mathrm{nu})$ mice. Immunol Invest 20: 605-621. doi: 10.3109/08820139109026241

11. Kusugami K, Fukatsu A, Tanimoto M, Shinoda M, Haruta J, Kuroiwa A, Ina $K$, et al. 1995. Elevation of interleukin6 in inflammatory bowel disease is macrophage- and epithelial celldependent. Dig Dis Sci 40: 949-959. doi: 10.1007/BF02064182

12. Livak K, Schmittgen TD. 2001. Analysis of relative gene expression data using real-time quantitative PCR and the $2^{-\Delta \Delta C t}$ method. Methods 25: 402-408. doi: 10.1006/meth.2001.1262

13. Meijssen MA, Brandwein SL, Reinecker HC, Bhan AK, Podolsky DK. 1998. Alteration of gene expression by intestinal epithelial cells precedes colitis in interleukin-2-deficient mice. Am J Physiol 274: 472-479.

14. Mestecky J, Russell MW, Elson C. 1999. Intestinal IgA: novel views on its function in the defence of the largest mucosal surface Gut 44: 2-5.

15. More J. 2013. Efecto de antígenos clostridiales con ácido retinoico sobre la expresión de citoquinas de la respuesta inmune humoral y celular de la mucosa intestinal de crías de alpacas (Vicugna pacos). Tesis de Magister. Lima: Univ Nacional Mayor de San Marcos. 104 p.

16. Moro M. 1987. Enfermedades infecciosas de las alpacas. Diarrea bacilar o enterotoxemia de las crías de las alpacas. Rev Camélidos Sudam 4: 8-13.

17. Pérez D, Maturrano L, Rosadio R. 2012. Genotipificación y subtipificación molecular de cepas de Clostridium perfringens aisladas en alpacas muertas por enterotoxemia. Rev Inv Vet Perú 23:272-279. doi: 10.15381/rivep.v23i3.909

18. Ramírez A, Huamán D, Ellis R. 1985. Enterotoxemia de la alpaca. INIPA-Programa colaborativo de apoyo a la investigación en rumiantes menores. Colorado State University. Serie de Reportes Técnicos 63: 1-40.

19. Roca V, Manchego A, Sandoval N, Lam Chiok K, Rivera H. 2014. Caracterización histológica y dinámica linfoide de las placas de Peyer en crías de alpaca durante los 45 primeros días de vida. Rev Inv Vet Perú 25: 341-349. doi: 10.15381/rivep.v25i3.10112

20. Ruiz V, Puig Y, Rodríguez M. 2010. Microbiota intestinal, sistema inmune y obesidad. Rev Cubana Invest Biomed 29: 364-397.

21. Sonoda E, Hitoshi Y, Yamaguchi N, Ishii T, Tominaga A, Araki S, Takatsu K. 1992. Differential regulation of IgA production by TGF- $\beta$ and IL-5: TGF- $\beta$ induces surface IgA positive cells bearing IL-5 receptor, whereas IL-5 promotes their survival and maturation into IgAsecreting cells. Cell Immunol 140: 158-172. doi: 10.1016/0008-8749(92)90184-Q

22. Takeuchi M, Alard P, Streilein J. 1998. TGF- $\beta$ promotes immune deviation by altering accessory signals of antigen-presenting cells. J Immunol 160: 1589-1597.

23. van Vlasselaer VP, Punnonen J, de Vries JE. 1992. Transforming growth factor-beta directs IgA switching in human B cells. J Immunol 148: 2062-2067. 